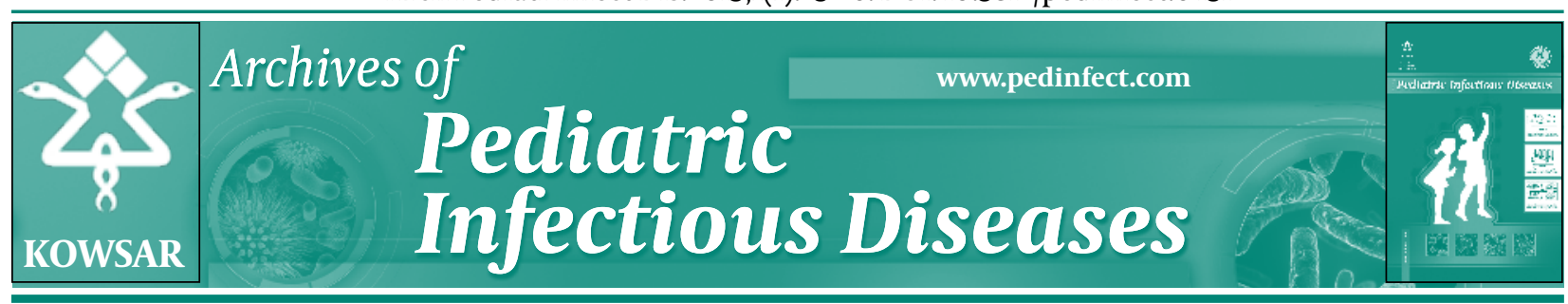

\title{
A Survey on Rotavirus Associated Diarrhea in 5 Main Cities of Iran
}

\author{
Farzaneh Jadali ${ }^{1}$, Abdollah Karimi ${ }^{2 *}$, Fatemeh Fallah ${ }^{3}$, Mohsen Zahraei ${ }^{4}$, Abdolreza Es- \\ teghamati ${ }^{4}$, Masoumeh Navidinia ${ }^{3}$, Saadat Adabian ${ }^{3}$ \\ ${ }^{1}$ Department of Pediatric Pathology, Pediatric Infections Research Center (PIRC), Mofid Children Hospital, Shahid Beheshti University of Medical Sciences, \\ Tehran, IR Iran \\ ${ }^{2}$ Pediatric Infections Research Center (PIRC), Mofid Children Hospital, Shahid Beheshti University of Medical Sciences, Tehran, IR Iran \\ ${ }^{3}$ Department of Medical Microbiology, Pediatric Infections Research Center (PIRC), Mofid Children Hospital, Shahid Beheshti University of Medical Sci- \\ ences, Tehran, IR Iran \\ ${ }^{4}$ Department of Pediatric Infectious Disease, Faculty of Medical Science, Tehran University of Medical Sciences, Tehran, IR Iran
}

A R T I C L E I N F O

Article type:

Original Article

Article history:

Received: 28 May 2012

Revised: 09 Jun 2012

Accepted: 20 Jun 2012

Keywords:

Enzyme-Linked Immunosorbent Assay

Serology

Gastroenteritis

Rotavirus

\begin{abstract}
A B S T R A C T
Background: Rotaviruses a major group of viruses that cause severe gastroenteritis in young children worldwide. Many different viruses can cause gastroenteritis, including Noroviruses, Adenoviruses, Sapoviruses, and Astroviruses. Serum antibody studies show that most of the children are infected with Rotavirus at least once in their life by the age of 3 . In the world, approximately 400-600 thousand children in poor countries die annually by Rotavirus-associated dehydration. Most of the deaths occur in these countries because of delay in treatment. Despite low death rates in industrialized countries, good hygiene and sanitation do not appear to reduce the prevalence or prevent the spread of Rotavirus.

Objectives: This study was aimed to detect Rotavirus in stool samples of infected patients using enzyme-linked immunosorbent assay (ELISA) serological method in 5 cities of Iran. Materials and Methods: In this descriptive study, 2988 stool samples of patients with acute gastroenteritis were collected from children's hospitals of 5 main cities of Iran. The samples were sent in frozen condition to pediatric infection research center in Tehran and stored at $-70^{\circ} \mathrm{C}$. ELISA test was performed for detection of Rotavirus antigens. The mean age of study population was 1 to 5 years.

Results: ELISA method on 2988 stool samples from 5 cities revealed rotavirus-positive results in 55.48\% cases, including $8.97 \%$ in Tehran, 7.56\% in Tabriz, 7.76\% in Mashhad, $14.42 \%$ in Shiraz, and $16.77 \%$ in Bandar Abbas). $59.2 \%$ of positive samples occurred in males and $40.8 \%$ in females.

Conclusions: Rotavirus is one of the major causes of gastroenteritis in children in Iran that can be easily detectable by ELISA method through which early diagnosis, treatment, and preventive vaccination can dramatically reduce mortality and morbidity rates of the disease.
\end{abstract}

Published by Kowsar Corp, 2013. cc 3.0.

- Implication for health policy/practice/research/medical education:

Rotavirus the most common cause of diarrhea in children and due to it's high morbidity a specific medication, Nowadays vaccination prevention is highly recommended.

- Please cite this paper as:

Jadali F, Karimi A, Fallah F, Zahraei M, Esteghamati A,Navidinia M, et al. A survey on Rotavirus Associated Diarrhea in 5 Main Cities of Iran. Arch Pediatr Infect Dis.2013;1(1): 23-6. DOI: 10.5812/pedinfect.6431

\footnotetext{
* Corresponding author: Abdollah Karimi, Pediatric Infections Research Center, Department of Pediatric Infectious Diseases, Mofid Children Hospital, Shariati St, Tehran, IR Iran. Tel:+98-9123951537, Fax:+98-22229641,E-mail: dr_akarimi@yahoo.com

DOI:10.5812/pedinfect.6431

(C) 2013 Pediatric Infections Research Center and Shahid Beheshti University of Medical Sciences; Published by Kowsar Corp.

This is an open access article distributed under the terms of the Creative Commons Attribution License(http://creativecommons.org/licenses/by/3.0), which permits unrestricted use, distribution, and reproduction in any medium, provided the original work is properly cited.
} 


\section{Background}

Gastroenteritis means the inflammation of stomach, small and large intestines. Rotavirus is the most common cause of severe gastroenteritis among children worldwide. Severe gastroenteritis results in approximately 800,000 deaths (1) annually by some bacteria (i.e. Staphylococcus aureus (2), Escherichia coli (3), Clostridium difficile, Yersinia enterocolitica, Salmonella, Shigella (4), Campylobacter (5), parasites (such as Giardia, Cryptosporidium) (6), and viruses. Some viruses causing gastroenteritis include Noroviruses, Adenoviruses, Sapoviruses, human Caliciviruses, and Astroviruses (7-9). Serum antibody studies show that likely all children have been infected with Rotavirus at least once in their life by the age of 3 .

Rotaviruses are ubiquitous; $95 \%$ of children worldwide are infected by the age of 3 to 5 . Theinfection is frequently asymptomatic caused by unusual strains of rotaviruses. The disease is most prevalent between ages 4 and36 months in children and sometimes occurs severely thatrequires hospitalization. Rotavirus infection in adults is usually subclinical but occasionally causes more severe clinical picture in parents of children with Rotavirus diarrhea, immune-compromised patients (including those with HIV), old individuals, and travelers to developing countries. In temperate climates, Rotavirus diarrhea occurs predominantly during the fall and winter; in tropical settings and in developing countries, seasonality is less marked.

Rotaviruses are shed in large numbers during episodes of diarrhea, and usually are detectable by antigen enzyme immunoassays (EIA) up to 1 week after infection or for more than 30 days in immune-compromised patients. The predominant mode of Rotavirus transmission is fecal-oral. Spread of the virus through respiratory secretions, person-to-person contact, or contaminated environmental surfaces has also been speculated because of high rates of infection in the first 3 years of life regardless of sanitary conditions, failure to document fecal-oral transmission in several outbreaks of Rotavirus diarrhea, and dramatic spread of rotavirus over large geographic areas in winter. Animal-to-human transmission does not appear to be common, although human rotavirus strains that possess a high degree of genetic homology with animal strains have been identified (10).

In the world, approximately 400-600 thousand children in poor countries die annually by Rotavirus-associated dehydration. Most of the deaths occur in these countries due to delay in treatment. Despite of low death rates in industrialized countries, good hygiene and sanitation do not appear to reduce the prevalence or prevent the spread of Rotavirus. Rotavirus particles are 65-75 nanometers in diameter, with a double protein shell and 11 unique strands of double-stranded RNA. The majority of Rotaviruses known to infect humans and animals share a common-group antigen and are termed group A Rotavi- ruses (11). Rotavirus gastroenteritis is manifested by some main symptoms such as abdominal pain, fever, diarrhea, lethargy, and vomiting that may lead to hypovolemic shock and dehydration (12). Diarrhea is the second most common cause of childhood mortality worldwide, estimated to be responsible for 1.76 million deaths annually between 2000 and 2003 and 1.87 million deaths in children under the age of 5 years in 2004 (13-15). Rotavirus can infect all children by the age of five regardless of socioeconomic status or environmental conditions (16). The world health organization (WHO) estimates that 527,000 childhood deaths are caused by Rotavirus disease each year (17). In developing countries, Rotavirus is the most common cause of childhood mortality due to severe diarrhea (18) Rotaviruses are the most common agents associated with benign seizures (19). A study in Iran reported 59.1\% Rotavirus-positive cases among children with acute gastroenteritis (20). The most dominant virus, group A, causes diarrheal diseases worldwide.

\section{Objectives}

This study was aimed to determine the prevalence of Rotavirus gastroenteritis in children under five years old with acute gastroenteritis using ELISA, a cheap and fast method, on 2988 samples, for detection of the virus by age, sex, and situation in 5 cities of Iran (21).

\section{Materials and Methods}

Stool specimens $(n=2988)$ were collected from patients under five years old with acute diarrhea hospitalized in Tehran, Shiraz, Tabriz, Bandar Abbas, and Mashhad, and referred to pediatric infection research center (PIRC) of Mofid children's hospital in freezed condition during April 2010 to March 2011 and stored at minus $70^{\circ} \mathrm{C}$. The cases were identified by reviewing hospital admission records of demographic characteristics and symptoms of patients.

A commercially available ELISA kit (Rotaclone; Meridian Bioscience Inc., Cincinnati, $\mathrm{OH}$ ) was used to detect group A Rotavirus antigen. (IDEIA Rotavirus, Dakocytomation Ltd. Denmark House, Angel Drove, Ely, cambsCB7 4ET, UK, Lot: $212985 \mathrm{kit})$. Results were read by an ELISA plate reader with the filters set at $450 \mathrm{~nm}$ and $620-650 \mathrm{~nm}$. Controls were included each time the kit was run.

\section{Results}

Fecal specimens from 2988 children below 5 years old with acute diarrhea hospitalized in 5 cities of Iran (Tehran, Shiraz, Tabriz, Bandar Abbas, Mashhad) from April 2010 to March 2011 were examined in PIRC of Mofid children's hospital, Tehran/Iran to know the prevalence of Rotavirus diarrhea from different locations of Iran using double antibody sandwich ELISA analysis. The prevalence of Rotavirus was the highest in Bandar Abbas (16.77\%) and 
Shiraz (14.42\%), Rotavirus and the least in Tabriz (7.56\%). Stool samples were positive for Rotavirus in $55.48 \%$ of cases (Figure 1). There was $59.9 \%$ of samples from male patients and $40.1 \%$ from females. Rotavirus diarrhea was significantly high $(P<0.01)$ in children between 11 to 20 months (43.28\%). Children from families of middle socioeconomic status (69.35\%) mostly suffered from the disease $(P<0.001)$. Peak incidence of rotavirus diarrhea was in winter (41.26\%) and showed inverse relation to temperature, humidity, and rainfall. Besides diarrhea, vomiting was a significant clinical manifestation.

Arch Pediatr Infect Dis.2012;1(1):in press. DOI: 10.5812/pedinfect.6431

Pediatric
KowSAR Infectious Diseases

A Survey on Rotavirus Associated Diarrhea in 5 Main Cities of Iran Farzaneh Jadali ${ }^{1}$,Abdollah Karimi ${ }^{2}$, Fatemeh Fallah ${ }^{3}$, Mohsen Zahraei ${ }^{4}$, Abdolreza Esteghamati $^{4}$, Masoumeh Navidinia ${ }^{3}$, Saadat Adabian ${ }^{3}$

'Pediatric Pathology Department, Pediatric I Ifection Research Center (PIRC) of Mofid Children Hospital, Shahid Beheshti University, Tehran, IR Iran ${ }^{2}$ Pediatric Infectious Disease Department, Pediatric Infection Research Center (PRRC) of Mofid Children Hospital Shahid Beheshti University Tehran, IR I ran ${ }^{3}$ Medical Microbiology Department, Pediatric Infection Research Center (PIRC) of Mofid Children Hospital, Shahid Behesht
${ }_{4}^{4}$ Pediatric Infiectious Disease Department, Faculty of Medical Science, Tehran university of Medical Sciences, Thehran, IR Iran

ARTICIFINFO

Figure 1. The Prevalence of Rotavirusin 5 Cities of Iran by ELISA Method

\section{Discussion}

Control of Rotavirus through improvements in hygiene and sanitation is difficult since this virus often transmits from person to person easily and therefore, the proportion of diarrhea deaths attributed to Rotavirus may increase. Eighty two percent of rotavirus deaths occur among children in undeveloped countries (22). In a study conducted in Ýzmir, Turkey, the reports showed that Rotavirus among children less than five years old is the most commonly detected etiologic agent responsible for $39.8 \%$ of acute gastroenteritis admissions (23). Another study in Iran showed 59.1\% Rotavirus-positive cases among 2198 children aged 5 years with acute gastroenteritis (24) that agreed with this study in which the prevalence was $55.48 \%$ (20). In other countries, the prevalence rates for Rotavirus-positive cases were reported as follows: Pakistan, 13.7\%; England, 43\% (25); Vietnam, 50\% (26); Poland, $41 \%$ (27): and Kuwait, 45\% (28). Of 260 children with acute diarrhea in Erbil, Iraq, 96 patients (37\%) were infected with Rotavirus (29).

In a pilot study conducted by Román in 2005,100 stool samples from patients with gastroenteritis were examined to determine the presence of Rotavirus using immunoassays and molecular diagnostic methods; the result was 11 Rotavirus-positive samples. Using reverse transcriptase-polymerase chain reaction (RT/PCR) method resulted in detection of 51 rotavirus-positive samples. These results substantiated the generally accepted concept that molecular techniques were more sensitive than serological diagnostic tests. In addition, these data suggest that Rotavirus is an important etiologic agent for gastroenteritis in local pediatric population (30).

Rotavirus gastroenteritis occurred in males and females.
In a study performed in Iran, the Rotavirus diarrhea in females less than five years old (18.0\%) was higher than that was detected in 187 (19\%) specimens tested by ELISA. Rotavirus was detected in 158 (28\%) out of 561 specimens collected from hospitalized children, whereas it was detected in only 29 (7\%) out of 423 children treated in oral rehydration unit (outpatients). Distribution of affected children less than 5 years old showed that 159 cases (83\%) occurred among children aged between 4 and 23 months, whereas only 8 cases (4.3\%) occurred in the first 3 months of life (31). In our study the distribution of Rotavirus occurred among children less than 2 years old (63\%).

In another study performed in Iran, the Rotavirus diarrhea in females less than five years old (18.0\%) was higher than that in males (13.7\%) of the same age (32) but our study and the other study showed different results with no relationship between Rotavirus infection and sex. Seasonality is obvious for Rotavirus infection so that majority of cases in temperate climates occur in winter months between November and February (33).

A multicenter study in 5 developing countries including Pakistan conducted by WHO CDD program revealed that only $1.8 \%$ of cases were presented with severe dehydration and these were mostly due to Rotaviruses; in the study all methods detected Rotavirus to varying degrees but ELISA was found to be the most sensitive method with $72.4 \%$ stools being positive (34).

In 2005 , Rotavirus was detected in 48 patients (10\%) in Saudi Arabia using latex agglutination test. ELISA detected 46/48 positive samples. Ten negative samples with latex test were also negative with ELISA. Infection with Rotavirus was more frequent among infants and children $<2$ years old, with a maximum incidence among children 0-12 months. The prevalence of Rotavirus infection in Saudi nationals was $3.1 \%$ compared to $6.9 \%$ in other nationalities (35).

Since the time of study was limited to 1 year, consideration of Rotavirus genotyping to detect the most prevalence genotypes for vaccination is necessary. In near future, continuous and broader surveillances on circular Rotavirus strains are required in Iran. Also, there is a great need for defining the prevalence of Rotavirus-associated disease burden and strain in Iran. We also need to conduct Rotavirus vaccine trials to assess its efficacy and safety in our settings. In addition, our data suggest that rotavirus is an important etiologic agent of gastroenteritis in local pediatric population. More extensive studies are necessary to determine the prevalence of Rotavirus in Iran in order to design effective control measures and protect our population against this pathogen. Agreement with study in 2003 by Phukan AC revealed that $23.27 \%$ of patients were affected by Rotavirus. Rotavirus diarrhea was significantly high in children under 2 years old (37.75\%)(36).

\section{Acknowledgments}

We thank Communicable Disease Center (CDC) of Min- 
istry of Health for giving permission to undertake the study and the management, and also staffs of Pediatric Infections Research Center in Mofid Children Hospital for their cooperation and support.

\section{Authors' Contribution}

None declared.

\section{Financial Disclosure}

None declared.

\section{Funding/Support}

Pediatric Infections Research Center (PIRC) of Mofid Children Hospital and Communicable Disease Center (CDC) of Ministry of Health.

\section{References}

1. Glass RI, Kilgore PE, Holman RC, Jin S, Smith JC, Woods PA, et al. The epidemiology of rotavirus diarrhea in the United States: surveillance and estimates of disease burden. J Infect Dis. 1996;174(Suppl1):S5-11.

2. de Jong JT, ten Brinke JM, van Ouwerkerk IM, Siebbeles MF, FitzJames IA, in 't Veld PH. [Large-scale, acute, bacterial gastroenteritis caused by the enterotoxin of Staphylococcus aureus after a barbecue]. Ned Tijdschr Geneeskd. 2004;148(43):2136-40.

3. Robins-Browne RM, Bordun AM, Tauschek M, Bennett-Wood VR, Russell J, Oppedisano F, et al. Escherichia coli and communityacquired gastroenteritis, Melbourne, Australia. Emerg Infect Dis. 2004;10(10):1797-805.

4. Dworkin MS, Shoemaker PC, Goldoft MJ, Kobayashi JM. Reactive arthritis and Reiter's syndrome following an outbreak of gastroenteritis caused by Salmonella enteritidis. Clin Infect Dis. 2001;33(7):1010-4.

5. Workman SN, Sobers SJ, Mathison GE, Lavoie MC. Human Campylobacter-associated enteritis on the Caribbean island of Barbados. Am JTrop Med Hyg. 2006;74(4):623-7.

6. De Leon R, Rose J, Bosch A, Torrella F, Gerba C. Detection of Giardia, Cryptosporidium and enteric viruses in surface and tap water samples in Spain. Int J Environ Health Res. 1993;3(3):121-9.

7. Minosse C, Zaniratti MS, Calcaterra S, Carletti F, Muscillo M, Pi sciotta M, et al. Application of a molecular panel to demonstrate enterotropic virus shedding by healthy and human immunodeficiency virus-infected patients. J Clin Microbiol. 2005;43(4):197981.

8. Basu G, Rossouw J, Sebunya TK, Gashe BA, de Beer M, Dewar JB, et al. Prevalence of rotavirus, adenovirus and astrovirus infection in young children with gastroenteritis in Gaborone, Botswana. East Afr Med J. 2003;80(12):652-5.

9. Shaw RD. Viral infections of the gastrointestinal tract. Current Opin Gastro.1994;10(1):74.

10. Uchida R, Pandey BD, Sherchand JB, Ahmed K, Yokoo M, Nakago$\mathrm{mi} \mathrm{T}$, et al. Molecular epidemiology of rotavirus diarrhea among children and adults in Nepal: detection of G12 strains with P[6] or $\mathrm{P}[8]$ and a G11P[25] strain. J Clin Microbiol. 2006;44(10):3499-505.

11. Kapikian AZ, Chanock RM. Rotavirus. In: Field BN, Knip DM, editors. Virology. New York: Raven Press Ltd;1990. p. 1353-404.

12. Grimwood K, Lambert SB. Rotavirus vaccines: opportunities and challenges. Hum Vaccin. 2009;5(2):57-69.

13. Bryce J, Boschi-Pinto C, Shibuya K, Black RE. WHO estimates of the causes of death in children. The Lancet. 2005;365(9465):1147-52.

14. Hogberg U. The World Health Report 2005: "make every mother and child count" - including Africans. Scand J Public Health. 2005;33(6):409-11.
15. Boschi-Pinto C, Velebit L, Shibuya K. Estimating child mortality due to diarrhoea in developing countries. Bull World Health Organ. 2008;86(9):710-7.

16. Rotavirus vaccine for the prevention of rotavirus gastroenteritis among children. Recommendations of the Advisory Committee on Immunization Practices (ACIP). MMWR Recomm Rep. 1999;48(RR-2):1-20.

17. Parashar UD, Burton A, Lanata C, Boschi-Pinto C, Shibuya K Steele D, et al. Global mortality associated with rotavirus disease among children in 2004. I Infect Dis. 2009;200(Suppl 1):S9-S15.

18. Widdowson MA, Steele D, Vojdani J, Wecker J, Parashar U. Global rotavirus surveillance: determining the need and measuring the impact of rotavirus vaccines. Infect Dis. 2009;200(Suppl 1):S1-8.

19. Morooka K. Convulsions and mild diarrhea (in Japanese). Shonika (Tokyo). 1982;21:131-7.

20. Eesteghamati A, Gouya M, Keshtkar A, Najafi L, Zali MR, Sanaei M et al. Sentinel hospital-based surveillance of rotavirus diarrhea in iran. J Infect Dis. 2009;200(Suppl 1):S244-7.

21. Khoury H, Ogilvie I, El Khoury AC, Duan Y, Goetghebeur MM. Burden of rotavirus gastroenteritis in the Middle Eastern and North African pediatric population. BMC Infect Dis. 2011;11:9.

22. Parashar UD, Hummelman EG, Bresee JS, Miller MA, Glass RI. Global illness and deaths caused by rotavirus disease in children. Emerg Infect Dis. 2003;9(5):565-72.

23. Kurugol Z, Geylani S, Karaca Y, Umay F, Erensoy S, Vardar F, et al. Rotavirus gastroenteritis among children under five years of age in Izmir, Turkey. Turk J Pediatr. 2003;45(4):290-4.

24. Nishio O, Matsui K, Oka T, Ushijima H, Mubina A, Dure-Samin A, et al. Rotavirus infection among infants with diarrhea in Pakistan. Pediatr Int. 2000;42(4):425-7.

25. Djuretic T, Ramsay M, Gay N, Wall P, Ryan M, Fleming D. An estimate of the proportion of diarrhoeal disease episodes seen by general practitioners attributable to rotavirus in children under $5 \mathrm{y}$ of age in England and Wales. Acta Paediatr Suppl. 1999;88(426):38-41.

26. Nishio O, Matsui K, Lan DT, Ushijima H, Isomura S. Rotavirus infection among infants with diarrhea in Vietnam. Pediatr Int 2000;42(4):422-4.

27. Mrukowicz JZ, Krobicka B, Duplaga M, Kowalska-Duplaga K, Domanski J, Szajewska H, et al. Epidemiology and impact of rotavirus diarrhoea in Poland. Acta Paediatr Suppl. 1999;88(426):5360.

28. Sethi SK, Al-Nakib W, Khuffash FA, Majeed HA. Acute diarrhoea and rotavirus infections in young children in Kuwait. Ann Trop Paediatr. 1984;4(2):117-21.

29. Ahmed HM, Coulter JB, Nakagomi O, Hart CA, Zaki JM, Al-Rabaty $\mathrm{AA}$, et al. Molecular characterization of rotavirus gastroenteritis strains, Iraqi Kurdistan. Emerg Infect Dis. 2006;12(5):824-6.

30. Roman E, Martinez I. Detection of rotavirus in stool samples of gastroenteritis patients. $P$ R Health Sci J. 2005;24(3):179-84.

31. Kheyami AM, Nakagomi T, Nakagomi O, Dove W, Hart CA, Cunliffe NA. Molecular epidemiology of rotavirus diarrhea among children in Saudi Arabia: first detection of G9 and G12 strains. J Clin Microbiol. 2008;46(4):1185-91.

32. Modarres S, Modarres S, Oskoii NN. Rotavirus infection in infants and young children with acute gastroenteritis in the Islamic Republic of Iran. East Mediterranean Health J.1995;1(2):210-4.

33. Gleizes O, Desselberger U, Tatochenko V, Rodrigo C, Salman N, Mezner Z, et al. Nosocomial rotavirus infection in European countries: a review of the epidemiology, severity and economic burden of hospital-acquired rotavirus disease. Pediatr Infect Dis J. 2006;25(1 Suppl):S12-21.

34. Ali NK, Bhutta ZA. A review of rotavirus diarrhea in Pakistan: how much do we know? J Coll Physicians Surg Pak. 2003;13(5):297-301.

35. Ghazi HO, Khan MA, Telmesani AM, Idress B, Mahomed MF. Rotavirus infection in infants and young children in Makkah, Saudi Arabia.J Pak Med Assoc. 2005;55(6):231-4.

36. Phukan AC, Patgiri DK, Mahanta J. Rotavirus associated acute diarrhoea in hospitalized children in Dibrugarh, north-east India. Indian J Pathol Microbiol. 2003;46(2):274-8. 